\title{
The reform and practical exploration of Chinese tourism culture curriculum
}

\author{
Lanlan Liu, a \\ ${ }^{1}$ Shool of Economic Management Harbin University Harbin China \\ aliulanlan_001@163.com
}

Keywords: Reform, Practical, Chinese tourism culture.

Abstract. Culture is the essence of tourism. The course of Chinese tourism culture is the core course of tourism management, In order to improve the teaching quality of tourism culture, This paper discusses the concept and mode of teaching reform of Chinese tourism culture from the five parts of curriculum orientation, curriculum objectives, curriculum design, curriculum implementation and curriculum assessment.

\section{《中国旅游文化》课程改革与实践探索 \\ 刘岗岗1, a \\ ${ }^{1}$ 哈尔滨学院地理与旅游管理学院, 哈尔滨, 黑龙江, 中国 \\ aliulanlan_001@163.com}

关键词：旅游文化; 课程改革; 实践探索

中文摘要. 文化是旅游的本质, 《中国旅游文化》课程是旅游管理专业的核心课程。为提高 旅游文化课程教学质量, 本文从课程定位、课程目标、课程设计、课程实施、课程考核五个 部分，探讨了 《中国旅游文化》课程的教学改革的理念和模式。

\section{1. 课程定位}

作为应用型本科院校, 学校在制定人才培养方案时, 将《中国旅游文化》这门课定位为 旅游管理专业的专业核心课, 这门课旨在培养和提高学习者的人文素养。它既是一门基础理 论课, 更是一门应用性、服务性、综合性的课程。《中国旅游文化》的授课对象为旅游管理 专业大一的同学, 这些同学, 大多数理论学习主动性不够, 但活泼好动、表现欲强。目前, 该课程的讲授大多停留在知识介绍层面, 对文化深层次产生的原因及内涵挖掘不够, 使得学 生在学习过程中处于被动接受的状态, 因此针对课程的学术性与学生知识基础薄弱的突出的 矛盾, 开展教学改革势在必行。《中国旅游文化》在专业课程体系中起着承上启下的作用, 它既是前续课程《旅游学概论》, 《旅游地理学》的延伸与扩展, 也是学生后续课程《旅游 产品设计与开发》、《旅游规划与开发》、《导游业务》的知识支撑, 它们共同构成了旅游 管理专业能力素质的培养主线。

\section{2. 课程目标}

依据学校对人才培养的总体要求制定了课程的总体目标：通过学习, 使学生全面提升自 己知识水平以及能力素质, 为将来运用相关文化知识从事导游员及旅游文化资源开发及规划 
等工作奠定基础。为了更好的进行人才培养，又从知识、能力、情感三个维度细化了总体目 标。知识目标为: 培养学生理解中国旅游文化的基本知识和原理。能力目标为: 培养和提高 学生鉴赏、识别旅游文化要素的能力; 利用旅游文化知识进行开展实践活动的能力。情感目 标为增强民族自豪感，培养学生爱国主义情怀。

\section{3. 课程设计}

本门课程所采用的教材是由中国旅游出版社刘亚轩主编的《中国旅游文化》。本课程的 总体设计理念为: 以能力为本位, 以职业功能为主线, 以项目为结点。为此依据“任务驱动” 的教学理念, 本门课注意培养学生三种能力即自主学习能力, 体验探究能力, 总结反思能力, 使学生由我学会向我会学转变。本课程共 54 学时, 分理论教学 (课堂教学) 与实践教学两大 部分。在课程设计中依据课程内容的框架结构及逻辑关系对整体教学内容进行了整合。将所 选教材的9章内容加以整合, 形成了三大体系七大模块。具体内容见下图 1

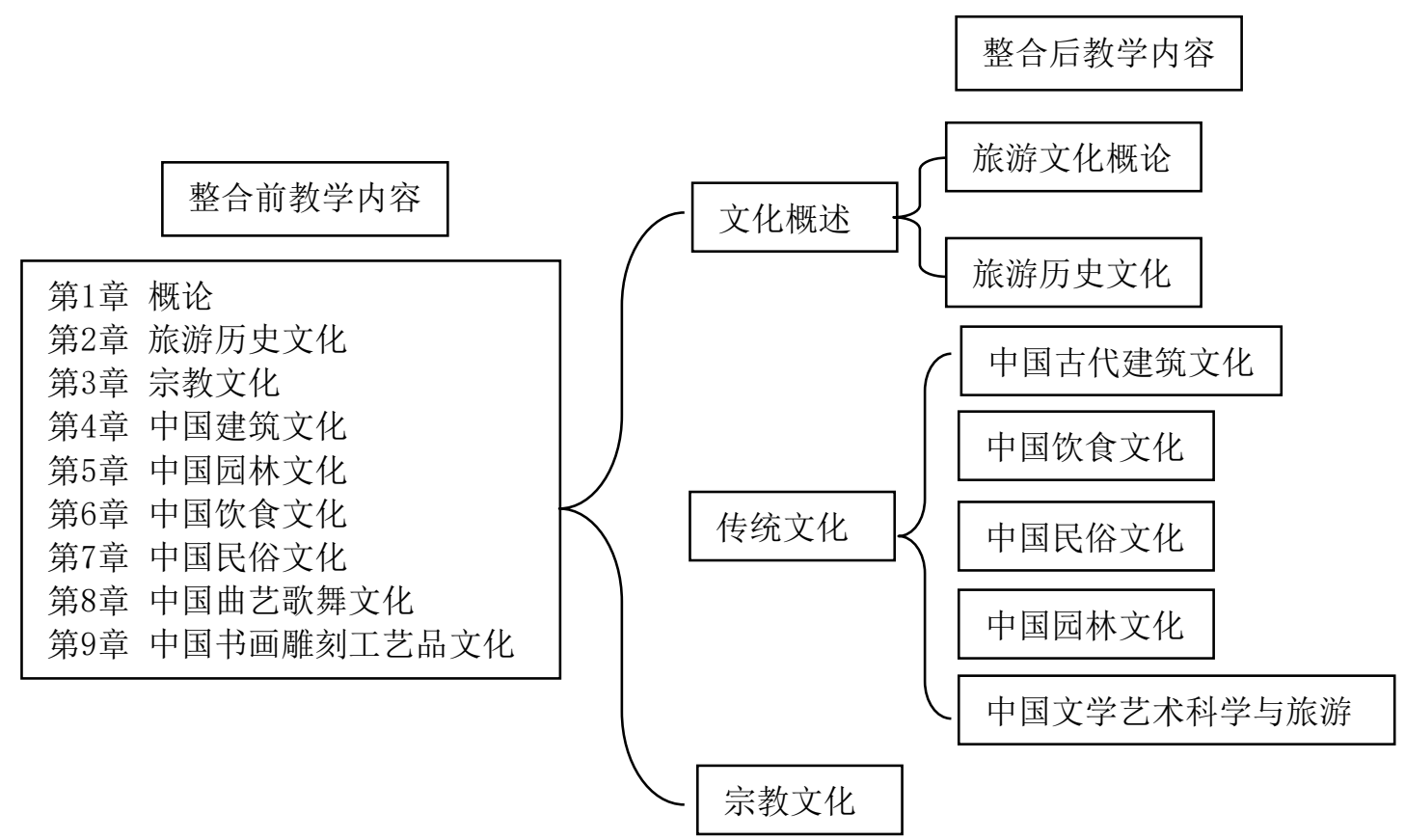

图1 教学模块构成图

针对七大模块所进行的理论与实践学时的具体分配。具体见表 1 
表 1 学时分配表

\begin{tabular}{|c|c|c|c|c|c|}
\hline $\begin{array}{l}\text { 序 } \\
\text { 号 }\end{array}$ & 主要内容 & 理论 & 实践 & 总计 & 重点内容 \\
\hline 1 & 文化概述 & 6 & 3 & 9 & $\begin{array}{l}\text { 家国秩序 仁义礼智—儒家文化与旅游 } \\
\text { 探索宇宙 别开生面——道家学派深奥的 } \\
\text { 哲理 }\end{array}$ \\
\hline 2 & 宗教文化 & 6 & 6 & 12 & $\begin{array}{l}\text { 土生土长的宗教——中国传统道教 } \\
\text { 文化移植与变异——佛教与中国传统文 } \\
\text { 化 }\end{array}$ \\
\hline 3 & 中国古代建筑文化 & 6 & 3 & 9 & 安居乐业的家园一中国传统居住文化 \\
\hline 4 & 中国饮食文化 & 4 & / & 4 & $\begin{array}{l}\text { 民以食为天一㑑传统饮食习俗 } \\
\text { 淡泊明志 宁静致远一中国古代茶文化 } \\
\text { 奋起沉沦 人耶酒耶一一国古代酒文化 }\end{array}$ \\
\hline 5 & 中国民俗文化 & 4 & 1 & 4 & 千里姻缘一线牵一一国传统婚姻习俗 \\
\hline 6 & 中国园林文化 & 4 & 3 & 7 & 中国园林的形式、风格及内涵 \\
\hline 7 & 中国文学艺术科学与旅游 & 6 & 3 & 9 & $\begin{array}{l}\text { 异彩纷呈 绚烂多姿——国古代艺术 } \\
\text { 彪炳千秋话格物一中国古代科学 }\end{array}$ \\
\hline $\begin{array}{l}\text { 合 } \\
\text { 计 }\end{array}$ & & 36 & 18 & 54 & \\
\hline
\end{tabular}

在实践教学环节, 课程立足当地特有旅游资源, 对应七大模块内容设置考察与实践任务, 力求让同学将理论与应用更好的结合起来。具体见表2。

表2 实践教学任务分配表

\begin{tabular}{|c|c|c|c|c|}
\hline 序 & 实践内容 & 实践地点 & $\begin{array}{l}\text { 学 } \\
\text { 时 }\end{array}$ & 重点内容 \\
\hline \multirow[b]{2}{*}{1} & \multirow{2}{*}{ 文化探索 } & \multirow{2}{*}{ 阿城金上京博物馆 } & \multirow[b]{2}{*}{3} & 地方文化的整体构成与历史传承认知 \\
\hline & & & & 体验构建金文化的先民们的文化创造 \\
\hline \multirow[t]{2}{*}{2} & \multirow[t]{2}{*}{ 宗教文化 } & 哈尔滨极乐寺 & \multirow[t]{2}{*}{6} & $\begin{array}{l}\text { 通过东北三省最大的佛教寺院了解佛 } \\
\text { 教建筑布局及文化 }\end{array}$ \\
\hline & & 哈尔滨松峰山 & & 体验东北最早道教胜地的文化 \\
\hline \multirow[t]{2}{*}{3} & \multirow[t]{2}{*}{ 古建筑、园林文化 } & 哈尔滨市道台府 & \multirow[t]{2}{*}{6} & $\begin{array}{l}\text { 体验中国传统的北方官式建筑和东北 } \\
\text { 地方建筑的建筑手法, 对具有中国民族 } \\
\text { 特点的青瓦四合院落进行赏析。 }\end{array}$ \\
\hline & & 哈尔滨市中国亭园 & & $\begin{array}{l}\text { 对中国 “亭” 的发展历史进行追溯, 对 } \\
\text { 杰出代表进行赏读 }\end{array}$ \\
\hline 4 & $\begin{array}{c}\text { 瓷器和玉器文化解 } \\
\text { 读 }\end{array}$ & 哈尔滨古玩城 & 3 & $\begin{array}{l}\text { 中国国粹瓷器和玉文化的观赏与初步 } \\
\text { 鉴别 }\end{array}$ \\
\hline 5 & 各地民俗文化比较 & 学生各自家乡 & 0 & $\begin{array}{l}\text { 通过假期社会调研, 收集解读各地民俗 } \\
\text { 文化精髓 }\end{array}$ \\
\hline $\begin{array}{l}\text { 合 } \\
\text { 计 }\end{array}$ & & & 18 & \\
\hline
\end{tabular}

\section{4. 课程实施}

课程的具体实施中，秉承课程设计的总体理念和着重培养的三种能力，将本课程实施过 程分为五个环节: 即自主学习、小组讨论、体验探究、展示点评和知识总结。其目的为突出 重点、攻克难点、强化认知。达到授之以鱼不如授之以渔的目的。

在这一部分，将以本门课中国古代茶文化为例来阐述实施过程。

在自主学习环节, 课前老师会布置收看与茶相关视频, 通过网课、慕课对茶文化基础知 识进行预习, 更好的明确学习目标和需要突破的疑惑点。在课堂教学中, 通过教师设疑: 我 
国历代为什么把饮茶作为风雅的文化生活? 引出本堂课的教学难点问题: 茶文化的四要素, 即为名茶、名水、雅器、清境; 茶与文统、道统的结合。

为了更好的突破难点, 在小组讨论环节, 老师通过布置讨论题目如: 人们常说“无酒不成 席”、“灯红酒绿”和“泛花邀坐客，代饮引情言”在意境上有什么区别？红楼梦中栊翠庵品茶描 写得十分精彩, 请结合小说中的描写讨论下品茶人为什么钟情于对茶器的追求? 中国是茶的 故乡, 中国人的文化基调更像茶, 儒释道三家文化核心不同, 但茶文化却都能与之适应, 这 是为什么? 让同学们围绕上一环节引出的茶文化四要素和茶与文统、道统的结合进行探讨, 进一步理解这方面知识, 从而突破难点。

在体验探究环节，通过教师布置实操性题目：北京茶馆与成都茶馆在所饮之茶、茶风、 茶韵上的区别? 中国丰富多彩的地域茶文化有哪些? 小明想去杭州旅游, 他想请你帮助设计 一条杭州茶文化旅游路线, 你要怎么设计? 抓住教学重点: 即对各地茶文化进行区别; 设计 茶文化旅游线路。从而实现做中学”、“做中教”课程对实接践、内容对接技能的教学理念。

之后通过展示点评环节攻克重点。通过学生相互讲评，发现问题，自主解决，体现了“以 学生为主体”的教学理念。从而发现学生的潜能, 培养学生团队精神和创新能力, 严谨细致的 工作作风。

课程实施的最后一个环节为知识总结, 老师通过重点难点强调、作业布置、作业批阅及 辅导, 进一步强化学生的课堂认知。

\section{5. 课程考核}

在课程考核方面紧紧围绕课程教学的总体目标, 注重考核的多样性、灵活性与效果性, 注重过程考核及终极考核的结合。任务考核（占30\%），具体为线路设计、调研报告。过程 考核（占30\%），具体为出勤、参与课堂教学情况、小组PPT展示情况、实践表现。期末考核 （占40\%），具体为结课论文。

\section{6. 结束语}

《中国旅游文化》作为旅游管理专业的一门核心课程, 其教学改革模式从之前以教师为 主体向以学生为主体转变, 力求通过实践进一步践行翻转课堂的教学理念。希望本门课程的 教学探索及研究成果能为旅游管理专业其他课程提供参考, 从而更好地推动旅游管理专业课 程的教学改革及实践探索。

\section{References}

[1] B.Jocy, M.Weil. Modes of Teaching[M].Beijing :China Light Industry Press,2002.

[2] Alison Smedley.Improving learning in the clinical nursing environment:perceptions of senior Australian bachelor of nursing students[J].Research in Nursing,2009(15):75-88.

[3] P.Cabilio and P.J.Farrell.A Computer_—Based Lab Supplement to Courses in Introductory Statistics[J].American Statistical Association,2001(3):228-232.

[4] Bradstreet,T.E.Teaching Introductory Statistics Courses so that Non statisticians Experience Statistical Reasoning[J]The American Statistician,1996(50): 69-78.

[5] Anne H.Margulies.OCWEvaluation Strategyand Plan[J].MITOPENCOURSEWARE.2003 .

[6] Sally M.Johnstone. Open Educational Resources Serve the World[J]. Educause Quarterly, 2005(28):15-18 .

[7] Mimi miyoung Lee.OOPS Tunung MIT Opencourseware into Chinese An analysis of a 
community of practice of global translators[J]. The International Review of Research in Open and Distance Learning, 2007(8) . 